\title{
Flipped Ophthalmology Classroom: A Better Way to Teach Medical Students
}

\author{
Ryan J. Diel, MD ${ }^{1}$ Armin Avdic, MS ${ }^{1}$ Pavlina S. Kemp, MD ${ }^{1}$ \\ ${ }^{1}$ Department of Ophthalmology and Visual Sciences, University of \\ Address for correspondence Pavlina S. Kemp, MD, Department of \\ lowa Hospitals and Clinics, lowa City, lowa \\ Ophthalmology, University of lowa Hospitals and Clinics, lowa City, IA \\ 52242 (e-mail: pavlina-kemp@uiowa.edu).
}

J Acad Ophthalmol 2020;12:e104-e109.

\begin{abstract}
Keywords

- flipped classroom

- education

- curriculum

- ophthalmology

Objective While medical education has generally progressed, advancements in ophthalmic education have been minimal. The flipped classroom technique is a research-supported approach to adult learning that encourages active participation. The effectiveness of widely implementing the flipped classroom modality in ophthalmology had not been studied. The purpose of this study was to evaluate a flipped classroom, primary care-focused curriculum for medical students in their ophthalmology clerkship.

Methods The ophthalmology clerkship curriculum was changed from a traditional, diagnosis-focused, lecture-based system to a chief complaint-based, flipped classroom structure. The study was performed over a 3-year period from 2016 (full traditional lecturebased system) to 2018 (full flipped classroom structure). Medical students' evaluations of the clerkship, recorded lecture viewership, and exam scores were retrospectively reviewed. Cohorts from study years 2016 and 2018 were used to assess knowledge acquisition and the attitudes of learners after implementing a flipped classroom structure.

Results The primary care-focused, flipped classroom received a higher clerkship rating than the diagnosis-based traditional classroom (mean 4.18 vs. 3.82, respectively, $p=0.008$ ). Students of the flipped classroom modality found the teaching sessions more valuable, experienced more direct interaction with faculty and residents, regarded the faculty and residents as excellent teachers, and received feedback that helped them assess their individual skills and progress. These improvements were made without changing test performance while only modestly increasing hours spent studying.

Conclusion A chief complaint-based, flipped classroom approach to the basic ophthalmology clerkship increased student satisfaction, without changing the amount of knowledge gained. This resulted in more valuable and effective learning experiences for medical students.
\end{abstract}

"Do you realize you are in the process of revolutionizing ophthalmology medical education?"

- Anonymous teacher following implementation of the flipped classroom

While medical education, adult learning theory, and the entire field of ophthalmology have progressed, there have been few reported advancements in ophthalmic education in medical school, with a gradual decrease in time devoted to ophthalmology curriculum. ${ }^{1}$ The flipped classroom technique is an adult learning methodology that promotes active participation and is overwhelmingly supported by educational research in the undergraduate sciences, engineering, and mathematics. ${ }^{2}$

The flipped classroom technique asks students to prepare on their own time before entering the classroom where faculty-led received

February 5, 2020

accepted

April 22, 2020
DOI https://doi.org/

10.1055/s-0040-1713394. ISSN $2475-4757$.
Copyright $\odot 2020$ by Thieme Medical

Publishers, Inc., 333 Seventh Avenue, New York, NY 10001, USA. Tel: +1(212) 760-0888.
License terms

$(\circledast) \Theta \circledast$ 
discussions and small group exercises take place. This may be via reading assigned text, watching prerecorded lectures or using other preparatory material. The approach is called "flipped" because the usual passive classroom lecture followed by individual problem sets is reversed to an individual lecture followed by classroom problem solving to maximize active discussion. The flipped classroom technique is overwhelmingly supported by education research. One meta-analysis of 225 studies found a consistent advantage of the flipped classroom technique over traditional lectures in both increased test scores and decreased failure rates across variations in class size, educator skill, course level, and course type. ${ }^{2}$

Tang et al and Lin et al demonstrated that the flipped classroom technique can be successfully implemented in the ophthalmic curriculum; however, these studies examined the effectiveness of the flipped classroom modality in only ocular trauma and glaucoma. ${ }^{3,4}$ Preparing recorded lectures and garnering faculty support requires significant time investment on the part of the lead faculty, as well as increased preparation time for students. With the pros and cons of a flipped classroom in mind, there is a gap in the literature regarding the effectiveness of implementing the flipped classroom modality across all topics in ophthalmic education. This study aims to analyze the effectiveness of implementing a complete curriculum with the flipped classroom technique for medical students on a 2-week rotation in ophthalmology. We hypothesize that a flipped classroom modality enhances overall student satisfaction and increases direct interaction with faculty members, with effective ophthalmology knowledge acquisition.

\section{Methods}

\section{Curriculum Structure}

The ophthalmology clerkship at the University of Iowa is a 2week "selective" rotation that includes a maximum of eight students per 2-week session and a total of over 100 medical students per year. Students can elect to complete the course after their third semester of medical school when they start clinical rotations.

Prior to 2017, a traditional classroom curriculum was in place characterized by all didactics in the form of eight 45minute lectures of preprepared slides presented by a rotating pool of faculty, fellow or rarely, resident lecturers, with minimal in-class discussion. Traditional lectures were based on curriculum objectives set by the American University Professors in Ophthalmology 5 and the curriculum was supplemented with two textbooks. ${ }^{6,7}$ Topics were tailored by faculty subspecialty, corresponding with anatomic or diagnostic category. These topics consisted of the following: comprehensive ophthalmology, glaucoma, neuro-ophthalmology, oculoplastics, optics, pediatric ophthalmology and strabismus, red eye, and retina.

A flipped classroom curriculum was implemented over the 2017 calendar year and completely enacted by 2018. Thus, 2016 was the last full year with the traditional curriculum and 2018 was taught in a flipped classroom manner entirely. In the flipped classroom model, students watched eight recorded lectures lasting between 22 and 35 minutes, each correlating with one chapter of the Basic Ophthalmology text. ${ }^{8}$ Based on updated recommendations of learning objectives, ${ }^{8,9}$ topics were adjusted with a chief complaint and primary care focus, and consisted of the following: acute vision loss, chronic vision loss, manifestations of systemic diseases in the eye, red eye, ocular and orbital injuries, neuroophthalmology, amblyopia and strabismus, and eyelid, lacrimal and orbital diseases. Time previously allotted to lectures was used for eight interactive case-based discussions related to the recorded lectures and its correlating textbook chapter, using patient scenarios from the course textbook. ${ }^{8}$ Discussions were scheduled according to discussion-leader availability, from a pool of 33 faculty assigned topics closest to their area of specialization, and five senior residents, who led the ocular and orbital injuries session, due to their on-call experience. Rotations had an enrollment of three to eight students, and discussion sessions included all students on the rotation.

Recorded lectures were created by the director of medical student education of the clerkship, each taking $\sim 8$ hours to create, record, and edit the content. Length of each recording was dependent by amount of content per chapter. All recorded lectures were available via an online video platform (Panopto, Seattle, WA), with corresponding slides sets available through an online course page. Students were encouraged to either watch the lectures or read the corresponding chapter or slide set (based on their preferred method of learning) prior to the topic's learning session. During the session, discussion of the case-based questions was led by faculty, fellows, or, less frequently, residents.

Throughout the study period, some other changes were made to improve the clerkship. Students were asked to have a feedback discussion with residents, fellows, or faculty at the end of their first week, starting in August 2018. An eye exam skills session was formalized and led in a near-peer paradigm by an ophthalmology intern, starting July 2018. In May 2017, the format of an extra credit project was changed from submission of an online written case report to a presentation of an ophthalmology topic of the student's choice, given to their peers on the second to last day of the clerkship. Additionally, clinical notes were read and commented upon by course director starting in February 2017.

On the last day of the clerkship, students completed a computerized 35-question multiple-choice examination developed at our institution as part of the traditional classroom curriculum. This same examination was used before 2016 and remained unchanged throughout the study period. Prior to taking the examination, all students were required to complete an evaluation of the course, consisting of an overall rating of the clerkship and 18 additional statements assessed with a 5-point Likert scale, 5 indicating the most favorable rating. The evaluation statements are listed in -Table $\mathbf{1}$.

\section{Study Structure}

Human subjects research determination was submitted through the Institutional Review Board, and the study was determined not to be human subjects research. A retrospective review of all student evaluations from calendar years 2016, 
Table 1 Student evaluations of the clerkship with traditional and flipped classroom curricula

\begin{tabular}{|l|l|l|l|c|}
\hline Question & $\begin{array}{l}\text { Traditional } \\
\text { mean } \pm \text { SD }\end{array}$ & $\begin{array}{l}\text { Flipped } \\
\text { mean } \pm \text { SD }\end{array}$ & p-Value & $\begin{array}{l}\text { Change in students rating 4 or 5 } \\
\text { (flipped vs. traditional) }\end{array}$ \\
\hline Overall rating of the clerkship & $3.82 \pm 1.00$ & $4.18 \pm 0.85$ & $0.008^{\mathrm{a}}$ & $17.3 \%$ \\
\hline $\begin{array}{l}\text { Course objectives were explained in } \\
\text { adequate detail }\end{array}$ & $4.29 \pm 0.86$ & $4.65 \pm 0.57$ & $<0.001^{\mathrm{a}}$ & $10.3 \%$ \\
\hline $\begin{array}{l}\text { Expectations for my participation in the } \\
\text { clerkship were made clear }\end{array}$ & $4.24 \pm 0.87$ & $4.52 \pm 0.72$ & $0.006^{\mathrm{a}}$ & $2.9 \%$ \\
\hline $\begin{array}{l}\text { Clerkship resources (syllabus, textbook, } \\
\text { website) aided my learning }\end{array}$ & $4.45 \pm 0.81$ & $4.63 \pm 0.72$ & $0.039^{\mathrm{a}}$ & $3.1 \%$ \\
\hline Teaching sessions were valuable & $4.39 \pm 0.71$ & $4.67 \pm 0.67$ & $<0.001^{\mathrm{a}}$ & $6.8 \%$ \\
\hline Faculty/preceptors were excellent teachers & $4.16 \pm 0.98$ & $4.44 \pm 0.89$ & $0.014^{\mathrm{a}}$ & $11.6 \%$ \\
\hline Residents/fellows were excellent teachers & $4.55 \pm 0.69$ & $4.82 \pm 0.45$ & $<0.001^{\mathrm{a}}$ & $5.2 \%$ \\
\hline $\begin{array}{l}\text { Clerkship activities and teaching } \\
\text { sessions were respectful of my time }\end{array}$ & $4.43 \pm 0.72$ & $4.65 \pm 0.66$ & $0.005^{\mathrm{a}}$ & $1.3 \%$ \\
\hline $\begin{array}{l}\text { Clinical skills specific to the clerkship } \\
\text { were demonstrated }\end{array}$ & $4.36 \pm 0.87$ & $4.45 \pm 0.79$ & 0.549 & $7.5 \%$ \\
\hline I was included as a member of the team & $3.70 \pm 1.06$ & $4.03 \pm 1.09$ & $0.013^{\mathrm{a}}$ & $10.7 \%$ \\
\hline I interacted directly with faculty/preceptors & $3.56 \pm 1.16$ & $4.06 \pm 1.22$ & $<0.001^{\mathrm{a}}$ & $15.8 \%$ \\
\hline I interacted directly with residents & $4.70 \pm 0.52$ & $4.84 \pm 0.52$ & $0.004^{\mathrm{a}}$ & $-0.01 \%$ \\
\hline $\begin{array}{l}\text { I was given autonomy and guidance } \\
\text { appropriate for my abilities }\end{array}$ & $3.37 \pm 1.26$ & $3.56 \pm 1.27$ & 0.254 & $7.8 \%$ \\
\hline $\begin{array}{l}\text { I learned procedural skills appropriate } \\
\text { to my abilities }\end{array}$ & $3.73 \pm 1.13$ & $3.95 \pm 1.11$ & 0.114 & $12.4 \%$ \\
\hline My clinical skills were directly observed & $3.63 \pm 1.28$ & $3.88 \pm 1.22$ & 0.137 & $8.7 \%$ \\
\hline $\begin{array}{l}\text { My clinical notes were read } \\
\text { and commented on }\end{array}$ & $2.78 \pm 1.46$ & $4.37 \pm 1.13$ & $<0.001^{\mathrm{a}}$ & $50.8 \%$ \\
\hline $\begin{array}{l}\text { I received feedback that helped me } \\
\text { assess my progress and skills }\end{array}$ & $3.43 \pm 1.24$ & $4.11 \pm 1.10$ & $<0.001^{\mathrm{a}}$ & \\
\hline $\begin{array}{l}\text { Contact with evaluators was sufficient } \\
\text { for fair evaluation of my skills }\end{array}$ & $3.61 \pm 1.18$ & $3.85 \pm 1.18$ & 0.102 & \\
\hline $\begin{array}{l}\text { Narrative evaluations reflected } \\
\text { my performance }\end{array}$ & $3.90 \pm 0.98$ & $4.20 \pm 1.06$ & $0.036^{\mathrm{a}}$ & \\
\hline
\end{tabular}

Abbreviation: SD, standard deviation.

andicates statistically significant difference $(p<0.05)$.

bercentage of students rating 5 increased from 72.6 to $88.8 \%$.

2017, and 2018 was performed, using individual, deidentified data. Individual viewership data from the video platform were obtained, with video completion defined as the percent of viewers at the 2:00 minute time point who were still viewing at 1 -minute remaining. Written clerkship examination results were also reviewed.

\section{Statistical Analysis}

Evaluation data was compared between calendar years 2016 and 2018 using the Mann-Whitney U test. This nonparametric test was chosen to identify significance in the setting of skew, which was seen due to students' tendency to overall give higher ratings on surveys. Significance was defined as a $p<0.05$. Evaluation data was presented as the mean of each survey question, since presenting the median yielded only ordinal numbers $(3,4$, or 5$)$ and was less informative than the mean. Data was also interpreted by consolidating evaluations scores of
4 and 5 and comparing the frequency of this favorable response between the traditional and flipped classroom cohorts.

Statistical analysis was performed using GraphPad Prism 8 (San Diego, CA) and MATLAB 9.6 (Natick, MA). No sample size calculation was performed, as this was a conveniencebased sample. All available data was included in the statistical analysis with the exception of one data point relating to hours spent studying in which one student reported studying 168 hours per week, which equates to every possible hour and thus not possible.

\section{Results}

In the calendar year 2016, 139 students chose ophthalmology as a selective rotation, including 79 men and 60 women. There were 45 second-year students, 27 third-year students, and 63 fourth-year students. In 2018, 108 students enrolled in the 
ophthalmology clerkship, including 54 men and 54 women. There were 11 second-year students, 41 third-year students, and 49 fourth-year students. No students repeated the rotation during the study period.

Out of the 19 possible survey items, all ratings increased from 2016 to 2018 (i.e., before, during, and after the curriculum change). Fourteen questions showed a statistically significant difference in mean rating between 2016 and 2018 including the overall rating of the clerkship, which increased from 3.82 to $4.18(p=0.008)$, moving the clerkship ranking from very last to 11 out of 16 .

Significant changes were observed in all 10 questions relating to curriculum and didactic education. The most pertinent improved responses to the selected questions include "Teaching sessions were valuable," "Residents/fellows were excellent teachers," and "I interacted directly with faculty/preceptors." These are the survey questions most directly focused at the flipped classroom change. Questions that addressed other changes in the clerkship were the most improved items overall, specifically "My clinical notes were read and commented on," "I received feedback that helped me assess my progress and skills," and "Course objectives were explained in adequate detail." Of note, the questions relating to the clinical aspects of the rotation were not significantly different, which was expected as changes were not made to the in-clinic component of the clerkship. Descriptive statistics for all survey items are shown in - Table 1.

When consolidated data combining answers of 4 and 5 was compared between curricula, $17.3 \%$ more students in the flipped classroom cohort gave the clerkship an overall favorable rating. After the curriculum change, teaching sessions were regarded as valuable by $6.8 \%$ more students, and faculty were perceived as excellent teachers by $11.6 \%$ more students. The structure of the classroom also led to increased interaction with faculty (15.8\% increased) and $10.7 \%$ more students felt included as part of the team. Interestingly, although resident interaction showed a $0.01 \%$ decrease in overall ratings of 4 and 5 , the mean score increased and the percentage of students choosing a score of 5 increased.

We identified an increase in the mean number of hours studied independently per week. On average, number of hours studied independently per week increased from 11.3 to 13.6 hours (95\% confidence interval of the difference 0.23 to $4.52, p=0.03$ ). However, the median remained 10 hours/week among both groups.

The feedback requirement affected 35 students in the 2018 cohort. The eye exam skills session reached 51 students. The change in clinical note feedback and extra-credit project affected all 108 students in the 2018 cohort.

Examination scores remained stable throughout the study period, with a mean exam score of $86.0 \% \pm 2.53 \%$ (standard deviation [SD]) during the traditional classroom, and $85.4 \% \pm 2.33 \%$ SD in the flipped classroom curriculum year, which was not a statistically significant change. Due to the anonymous nature of evaluation data, correlation between scores and final grade was not possible.

When the flipped classroom curriculum was completely enacted, $89.0 \%$ of all lecture views that started viewing the prerecorded lecture video (defined as viewing at 2 minutes) completed watching the lecture (defined as viewing with 1minute remaining). Viewing the lecture was not mandatory, and completion varied from 75.0 to $97.6 \%$ between the different lecture topics. Roughly, $94 \%$ of students in the course began viewing the lecture videos (range, 75-100\%).

There was no significant change in the number of students applying to ophthalmology residency as a result of this curriculum change.

\section{Discussion}

In 1972, Worthen proposed that medical students spend at least $5 \%$ of their time learning ophthalmology, since an average physician in practice will spend $5 \%$ of his or her time treating ophthalmic problems. Five percent of a 4-year curriculum equates to 7 weeks of exposure. ${ }^{10}$ Despite the repeated emphasis on ophthalmology education for future primary care providers, ${ }^{1,11-13}$ ophthalmic education in medical school has become increasingly sparse and often absent. ${ }^{1}$ As Shah et al eloquently state, "There continues to be a gradual erosion of the role of ophthalmic education in the standard medical school curriculum."13

Various approaches to improve ophthalmic education have been made including the use of e-modules, ${ }^{14}$ multimedia tools, ${ }^{15}$ and friendly peer-to-peer learning using fundus photographs. ${ }^{16}$ Not surprisingly, today's generation of learners strongly favors electronic learning modalities when compared with traditional lecture-based formats. ${ }^{17}$ Additionally, the advent of the "flipped classroom" technique has also been used within ophthalmology, ${ }^{3,4}$ to a limited extent, with both pros and cons. In this study, we found that implementing a primary care-focused, fully flipped classroom modality through the use of supplemental electronic modules to teach medical students ophthalmology resulted in higher overall clerkship satisfaction scores, and students found increased value and closer contact in the teaching sessions by both faculty and residents. Additionally, we found that implementing a flipped classroom model did not negatively affect knowledge acquisition or result in significantly increased time spent studying outside of the clinic.

One can make a strong argument for the flipped classroom approach to medical education due to the nature of medical decision-making. Students and residents are ideally learning to apply knowledge and solve problems in the clinic or operating room. In fact, problem-based, case-based and team-based learning approaches in medical schools have well-established efficacy and are now widely adopted. ${ }^{18,19} \mathrm{~A}$ recent study performed by Tang et al compared the flipped classroom and lecture-based classroom techniques in the ophthalmology clerkship. Students were assigned to two groups, a flipped group and a traditional group. Whereas the traditional group had in-class lectures, the flipped classroom group was asked to watch online videos, read study material, and optionally prepare and present a presentation to the class. The flipped classroom modality motivated students to learn about ocular trauma, enhanced understanding of the course material, and helped students prepare for the final exam. ${ }^{3}$ 
Similarly, Lin et al found that a flipped classroom environment provided greater satisfaction among students and was more enjoyable than lecture-based format. ${ }^{4}$ In this study, we show the effectiveness of applying this concept to the entire ophthalmology curriculum, and provide a successful model of the flipped classroom.

Overall satisfaction scores were higher in the flipped classroom when compared with the previous traditional lecture model, and students found the interactive teaching sessions, led by both faculty and residents, to be more valuable. Examination scores, although written for the traditional curriculum, did not suffer with the flipped classroom format. Though we did not see an improvement in scores as is typical of active learning modalities, ${ }^{2}$ there was no significant difference between traditional and flipped classroom modalities and overall performance score means remained above $85 \%$. The lack of improvement in test scores may be because the exam was written to test knowledge specifically taught by the traditional curriculum, and importantly did not decrease despite the change to a primary care-focus in the clerkship.

Students were allowed to read the textbook, review the slide set, or watch the recorded lecture, based on their preferred learning style, which may have improved their satisfaction. Despite a small increase in the mean hours spent studying outside of the clinic hours, the median remained unchanged; thus, this difference is unlikely to be perceived as significant by students. This is in stark contrast to the studies by both Tang and Lin in which students in flipped classrooms spent significantly more time preparing and felt a higher burden and pressure to perform. ${ }^{3,4}$

The curriculum change allowed for a more primary carefocused approach to teaching ophthalmology. The traditional curriculum was constructed based on faculty subspecialty, asking students to categorize a patient's complaint based on anatomy (i.e., retinal detachment), rather than chief complaint (acute vision loss, without pain). A renewed focus on the course's learning objectives ${ }^{9}$ resulted in an approach to prepare a primary care physician for common presenting complaints pertaining to eye health. Although this required some faculty to teach topics outside of their subspecialty, this methodology will allow for a widely-available ophthalmology curriculum for medical schools across the country, as well as internationally. In a time of decreasing emphasis on ophthalmology across medical curricula, ${ }^{13}$ medical students interested in primary care specialties, such as internal medicine, family medicine, emergency medicine and others, may benefit from this exposure. Nurse-practitioners and physician assistants, who are often frontline responders for eye complaints, can also refresh and expand their ophthalmology knowledge. Future ophthalmology interns could also be provided this foundation on which to build their clinical knowledge base.

At most teaching institutions, faculty are asked to teach medical students. Nevertheless, given the myriad responsibilities facing academic physicians (i.e., mentoring residents and fellows, and clinical, surgical and research duties), teaching duties must not only respect faculty time, but should also be intrinsically rewarding. Anecdotally, faculty reception was positive, citing increased student engagement that added to their satisfaction in teaching, although no formal data was collected.

The traditional classroom curriculum was administered by a pool of lecturers who adapted the lecture material and style of administration to their own preference. This limitation also highlights another reason to standardize the curriculum via recorded lectures; a recorded curriculum ensures that all students have the same foundation of knowledge despite differences in instructors.

The number of hours spent studying independently is subjective and plagued by inaccuracies. One example is a student who reported studying 168 hours/week, which equates to every possible hour. These inaccuracies may have been further complicated by students being given the option to choose if they wanted to view the video or read the material in the textbook. Lastly, the video could have been running without active engagement by the student. These variables may have confounded the viewership data to approximate levels.

The cost of implementing this curriculum change is primarily time of planning, developing, and recording lecture material and discussion cases. Lecture recording software was available through the academic institution, and other free options exist as well. Although not directly reimbursed, many clerkship directors have some financial compensation and curriculum development is part of their duties. Additionally, curriculum development is looked upon favorably by promotions committees. Time and cost of maintaining this curriculum have been essentially zero, although it is anticipated that as technology advances, the lectures will periodically need revision to prevent an outdated appearance. Our goal is to share this flipped classroom curriculum nationally, to decrease redundancy of effort in developing this content by other medical schools. We believe the benefits of this outweigh the costs.

The results of this study must also be interpreted in the setting of its limitations. First, this study is retrospective, and comparisons are being made across different cohorts of students. Second, and more importantly, although the change to a primary care-based flipped classroom format was by far the largest change in the curriculum, other incremental changes as noted above were also implemented. The effort to iteratively improve upon multiple aspects of the clerkship experience was not paused to study the flipped classroom in isolation. Required feedback sessions were added, and the slit-lamp training session was replaced by an intern-led 45-minute ophthalmology exam skills session on the first day of the clerkship. Clinical notes were critiqued by the clerkship director, as shown by the corresponding significantly improved evaluation score. Perhaps the increased attention to medical student education may have had a department-wide influence on faculty-student interactions outside of the didactic sessions. Ultimately, this article outlines an approach to turn a poorly performing clerkship (last among all the departments) to a more respectable performance (11th of 16 clerkships), which one change, no matter how significant, is unlikely to achieve. 
Despite these limitations, this study is the first to analyze the efficacy of implementing a standardized flipped classroom to an entire ophthalmology curriculum. Our results demonstrate that satisfaction and teaching effectiveness are significantly higher when ophthalmology curriculum is delivered via a chief complaint-focused flipped classroom model without compromising exam scores or significantly increasing the time students spent preparing outside of the classroom. Future directions include assessing efficacy using a pre- and postmodule questionnaire, measuring teacher satisfaction and attitudes toward a flipped classroom, and ideally, analyzing long-term retention of knowledge by the students. We hope to make this curriculum, including new interactive case-based discussions, available nationally for those interested in the benefits of a flipped classroom technique for teaching ophthalmology to medical students.

\section{Conclusion}

Without affecting the knowledge gained, student satisfaction increased through the use of a primary care-based flipped classroom. A flipped classroom approach to the basic ophthalmology medical student clerkship results in valuable and effective learning experiences for the next generation of physicians at the front line of eyecare.

Note

Paper presented at Association of University Professors in Ophthalmology Annual Meeting (AUPO), January 31, 2020.

\section{Funding}

None.

\section{Conflict of Interest}

None declared.

\section{Acknowledgment}

The authors wish to acknowledge Michelle Snyder, medical student coordinator, for her work managing the updated curriculum and guiding students through these changes.

\section{References}

1 Succar T, Grigg J, Beaver HA, Lee AG. A systematic review of best practices in teaching ophthalmology to medical students. Surv Ophthalmol 2016;61(01):83-94
2 Freeman S, Eddy SL, McDonough M, et al. Active learning increases student performance in science, engineering, and mathematics. Proc Natl Acad Sci U S A 2014;111(23):8410-8415

3 Tang F, Chen C, Zhu Y, et al. Comparison between flipped classroom and lecture-based classroom in ophthalmology clerkship. Med Educ Online 2017;22(01):1395679

4 Lin Y, Zhu Y, Chen C, et al. Facing the challenges in ophthalmology clerkship teaching: is flipped classroom the answer? PLoS One 2017;12(04):e0174829

5 Mottow-Lippa L. Ophthalmology in the Medical School Curriculum: Reestablishing our Value and Effecting Change. Ophthalmology 2009;116(07):1235-1236.e1

6 Harper R. Basic Ophthalmology. San Francisco, CA: American Academy of Ophthalmology; 2010

7 Trobe J. The Physician's Guide to Eye Care. San Francisco, CA: American Academy of Ophthalmology; 2012

8 Allen R, Harper R. Basic Ophthalmology: Essentials for Medical Students. San Francisco, CA: American Academy of Ophthalmology; 2016

9 Graubart EB, Waxman EL, Forster SH, et al. Ophthalmology objectives for medical students: revisiting what every graduating medical student should know. Ophthalmology 2018;125(12): 1842-1843

10 Worthen DM. Ophthalmology for medical students: objectives. Arch Ophthalmol 1972;88(03):314-315

11 Stern GA; The Association of University Professors of Ophthalmology Education Committee. Teaching ophthalmology to primary care physicians. Arch Ophthalmol 1995;113(06):722-724

12 Albert DM, Bartley GB. A proposal to improve ophthalmic education in medical schools. Ophthalmology 2014;121(06):1157-1159

13 Shah M, Knoch D, Waxman E. The state of ophthalmology medical student education in the United States and Canada, 2012 through 2013. Ophthalmology 2014;121(06):1160-1163

14 Bandhu SD, Raje S. Experiences with E-learning in ophthalmology. Indian J Ophthalmol 2014;62(07):792-794

15 Steedman M, Abouammoh M, Sharma S. Multimedia learning tools for teaching undergraduate ophthalmology: results of a randomized clinical study. Can J Ophthalmol 2012;47(01):66-71

16 Krohn J, Kjersem B, Høvding G. Matching fundus photographs of classmates. An informal competition to promote learning and practice of direct ophthalmoscopy among medical students. J Vis Commun Med 2014;37(1-2):13-18

17 Petrarca CA, Warner J, Simpson A, et al. Evaluation of eLearning for the teaching of undergraduate ophthalmology at medical school: a randomised controlled crossover study. Eye (Lond) 2018;32 (09):1498-1503

18 Soriano RP, Blatt B, Coplit L, et al. Teaching medical students how to teach: a national survey of students-as-teachers programs in U.S. medical schools. Acad Med 2010;85(11):1725-1731

19 Yu TC, Wilson NC, Singh PP, Lemanu DP, Hawken SJ, Hill AG. Medical students-as-teachers: a systematic review of peerassisted teaching during medical school. Adv Med Educ Pract 2011;2:157-172 